Berit Geuenich

\title{
Die Bestimmung des anwendbaren Rechts im Falle der internationalprivatrechtlichen Verweisung auf einen territorialen Mehrrechtsstaat
}

\author{
Rechtsvergleich, Haager Übereinkommen, Art. 4 Abs. 3 EGBGB, Europäisches IPR
}

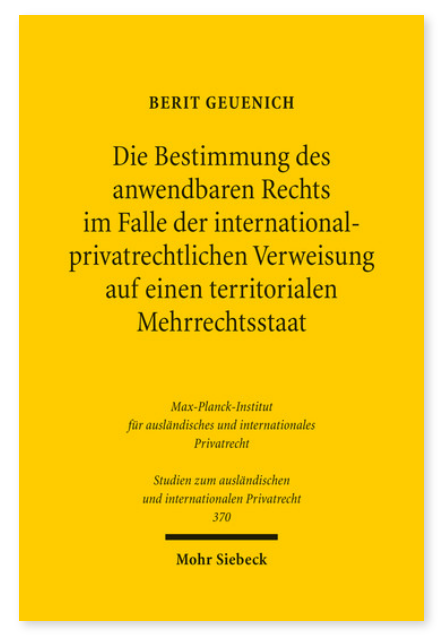

2017. XXXIV, 487 Seiten. StudIPR 370

ISBN 978-3-16-154854-3

DOI 10.1628/978-3-16-154854-3

eBook PDF 99,00€

ISBN 978-3-16-154853-6

fadengeheftete Broschur 99,00€
Bei der Bestimmung des anwendbaren materiellen Rechts im Falle eines Sachverhalts mit grenzüberschreitenden Bezügen stößt der Rechtsuchende bisweilen auf territoriale Mehrrechtsstaaten, innerhalb derer mehrere Rechtsordnungen in verschiedenen räumlichen Gebieten nebeneinander existieren. Dann fragt sich, wie aus den verschiedenen Rechtsordnungen eine einzelne Partikularrechtsordnung auszuwählen ist.

Auf diese Frage nach der Unteranknüpfung, eines der umstrittensten Probleme des IPR, sucht die Autorin eine Antwort, sowohl auf nationaler als auch auf europäischer Rechtsebene. Dazu betrachtet sie rechtsvergleichend die historischen Ursprünge der Problembehandlung, untersucht die Entwicklung der Regelungen in den Haager Übereinkommen, die nationale Vorschrift des Art. 4 III EGBGB sowie die Unteranknüpfungsregelungen der Europäischen Verordnungen und bietet abschließend einen Lösungsvorschlag.

Berit Geuenich Geboren 1987; Studium der Rechtswissenschaft in Köln und Paris (Sorbonne I); 2011 Erstes Staatsexamen; Referendariat am Landgericht Köln mit Station bei der Ständigen Vertretung der Vereinten Nationen in New York; 2015 Promotion; 2016 Zweites Staatsexamen.

Jetzt bestellen:

https://mohrsiebeck.com/buch/die-bestimmung-des-anwendbaren-rechts-im-falle-der-internationalprivatrechtlichenverweisung-auf-einen-territorialen-mehrrechtsstaat-9783161548543?no_cache=1 order@mohrsiebeck.com

Telefon: +49 (0)7071-923-17

Telefax: +49 (0)7071-51104 